\title{
Uterine Corpus Carcinoma and Carcinosarcoma TNM Finding v8
}

National Cancer Institute

\section{Source}

National Cancer Institute. Uterine Corpus Carcinoma and Carcinosarcoma TNM Finding

v8. NCI Thesaurus. Code C139757.

A finding about one or more characteristics of uterine corpus carcinoma or carcinosarcoma, following the rules of the TNM AJCC v8 classification system. This classification system does not apply to uterine corpus sarcomas: leiomyosarcomas, endometrial stromal sarcomas, and adenosarcomas. These sarcomas are staged according to the classification for uterine corpus sarcomas. (from AJCC 8th Ed.) 